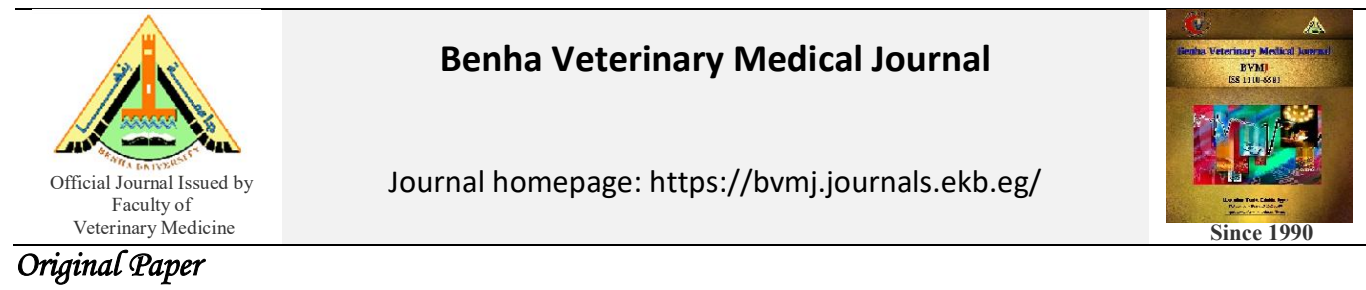

\title{
Role of Asparagus racemosus root in the amelioration of hepatocellular carcinoma in rat
}

Yakout, A. El-senosi ${ }^{1}$; Samy Aziza ${ }^{1}$; Sawsan Elsonbaty ${ }^{2}$ and Aboalella, M.S ${ }^{1}$

${ }^{I}$ Department of Biochemistry, Faculty of Veterinary Medicine, Benha University, Egypt.

${ }^{2}$ Radiation Microbiology department, National Center for Radiation Research and Technology, Atomic Energy Authority.

\begin{tabular}{l} 
ARTICLE INFO \\
\hline Keywords \\
Hepatocellular carcinoma, \\
Asparagus racemosus \\
p53 \\
SOD \\
CAT \\
\\
\hline Received $27 / 03 / 2021$ \\
Accepted $01 / 04 / 2021$ \\
Available On-Line \\
01/07/2021
\end{tabular}

\begin{abstract}
The purpose of this study was to look into the antitumor activity of Asparagus racemosus root (AR) against hepatocellular carcinoma (HCC) in male rats that had been induced experimentally. Fifty white albino rats were categorized randomly to five groups. Group I act as a negative monitor. Group II was given DEN by gavage at dose of $(20 \mathrm{mg} / \mathrm{kg} \mathrm{b}$.w/day/12 weeks). Group III rats were given $A R(200 \mathrm{mg} / \mathrm{kg}$ b.w/18 weeks) via gavage. Group IV rats were given DEN at dose of $(20 \mathrm{mg} / \mathrm{kg}$ b.w/day $/ 12$ weeks and then $A R$ at dose of $200 \mathrm{mg} / \mathrm{kg} \mathrm{b}$.w $/$ 6 weeks. Group V rats were given $A R$ at dose of $(200 \mathrm{mg} / \mathrm{kg} \mathrm{b.w} / 6$ weeks before administration of DEN dose of $(20 \mathrm{mg} / \mathrm{kg}$ b.w/day/12 weeks) till end of experiment. According to the findings, DEN treatment increased serum liver function enzymes ALT, AST, and ALP while decreasing the activity of hepatic antioxidant enzymes (SOD and CAT). DEN raised IL-6 levels while decreasing the apoptotic marker p53. Asparagus supplementation prior to or after DEN administration significantly reduced DEN toxicity and mutagenic effects, particularly when used as a protective. According to the findings, Asparagus racemosus roots should be used as an antioxidant and anti-tumor.
\end{abstract}

\section{INTRODUCTION}

Liver cancer is still a global health problem, and its prevalence is increasing (Villanueva, 2019, Liovet et al., 2021). By 2025, it is expected that more than 1 million people will be diagnosed with carcinoma per year (International Agency for Research on Cancer. GLOBOCAN 2018). Hepatocellular carcinoma (HCC) is the most common form of liver cancer, accounting for $90 \%$ of all cases. Non-alcoholic steatohepatitis (NASH), which is linked to diabetes or metabolic syndrome, is the fastestgrowing cause of HCC, particularly in the West (Estes et al., 2018). Aristolochic acid and tobacco have also been identified as key pathogenetic cofactors in HCC based on mutational signatures (Schulze et al. 2015). Cirrhosis, ingestion of aflatoxin B1-contaminated food, chronic alcohol intake, and hepatitis $\mathrm{B}$ and $\mathrm{C}$ viral infections are all major risk factors for HCC growth (Roy and Gadad, 2016). Because of increasing incidence at unprecedented rates, late detection, a lack of conclusive care, and a poor prognosis, the threat of this deadly cancer is expected to grow in the future (Aly et al., 2019).

Plants with medicinal properties may have been used in folklore for thousands of years. Shatavari is another name for Asparagus racemosus, which belongs to the liliid monocot family. It's a woody climber that can be found in low-lying forest areas in India, mostly in tropical and subtropical climates (Gomase and Sherkhane, 2010). The roots are cylindrical, fleshy, tuberous, and creamy yellow in

* Corresponding author: dr.mohamed_lab@yahoo.com appearance. The plant is used as a lactagogue (Sharma et al., 1996), has anticandidal activity (Uma et al., 2009), and is used to treat a variety of diseases such as diarrhea, dysentery, rheumatism, breakdown, and as an aphrodisiac (Uma et al., 2009 and Rajeshwar et al., 2014). There have been many studies have shown that Asparagus racemosus root extracts have antioxidant and anti-cancer activity against colon tumors (Bhutani et al., 2010), breast and kidney tumors (Mitra et al., 2012), HCC (Agrawal et al., 2008), and lung tumors (Agrawal et al., 2008). (Kongkaneramit et al., 2011). Diethylnitrosamine (DEN) is a potent genotoxic nitrosamine that has been shown to cause nuclear enzymes damage inked to DNA repair or replication and is widely used in animal models to cause liver tumor. It has been shown that DEN is metabolized into its active alkyl radical metabolite, which interacts with DNA, causing mutations and aberrations of chromosomes, potentially leading to hepatocarcinogenesis (Hassan et al., 2014). Furthermore, DEN formed active metabolites by cytochrome isoform 2E1 (CYP 2E1) boost oxidative stress, resulting in cytotoxicity (Mandal et al., 2008).

Serum liver enzymes such as (ALT), (AST) and (ALP) are tested routinely and automatically in many clinical settings and are commonly elevated in patients with liver diseases and thus may reflect the status of liver injury physicians generally use significant elevations of liver enzyme levels as complementary markers to aid the diagnosis of various diseases (Hann et al., 2012).

Development and progression of HCC are well associated with the oxidative stress status that produced by increasing 
level of reactive oxygen species (ROS) resulting distortion and decrease the antioxidant activity in the tissues. However, thedecrease of the antioxidant enzymes activity (superoxidedismutase and catalase) caused the increase of hepatocytesin the cirrhotic livers. The production of cytokines, ROS, and inflammation-mediated events leads to tumor formation( Hassan, et al., 2014).

The p53 gene is the most well-known candidate for genetic modifications in human tumors because it is a potent tumor suppressor. The p53 protein inhibits proliferation of abnormal cell and is an effective defense mechanism against the development of cancer. Tumorigenic cells contain p53mutant forms, while normal cells express wild type p53 (Rotter et al., 1993; Sluss and Jones, 2003). Real-time quantitative PCR is often used to identify cells clusters expressing a mutant conformation of the $\mathrm{p} 53$ protein (Rebel et al., 2001, Agrawal et al., 2008).

\section{MATERIAL AND METHODS}

\subsection{Experimental animals:}

Fifty white male albino rats, aged 10-12 weeks and weighing $100-120 \mathrm{~g}$, were used in this work. Rats were collected from the laboratory animal research unit, Moshtohor, Benha University's Faculty of Veterinary Medicine. The rats were kept in normal light and temperature conditions, with free access to a standard ordinary pellet diet and unlimited tap water. Before the experiment began, the animals were given a 10-day acclimatization period. The experimental protocols were approved by the Animal Care and Use committee at Benha University and are in accordance with the National Institute of Health Guide for the Care and Use

2.2. Chemicals:

2.2.1 Diethylnitrosamine (DEN): The chemicals used in this research were as follows: (DEN) was obtained from Sigma Chemical Co. (St. Louis, USA). Diethylnitrosamine was diluted in physiological saline and given as a $20 \mathrm{mg} / \mathrm{kg}$ body weight dose (El-Shahat, et al., 2012).

2.2.2 Asparagus racemosus root powder: was purchased from Shaanxi Pioneer Biotech Co., Ltd in China and prepared as an aqueous extract root powder using distilled water to be administered at a dosage of $(200 \mathrm{mg} / \mathrm{kg}$ body weight) (Agrawal et al., 2008).

2.3. Experimental Design:

Animals were divided into five groups, (ten rats each), as follows:

2.3.1 Group (1): Negative control: During the experiment, rats were given $1 \mathrm{~mL}$ of physiological saline orally by gavage every day.

2.3.2 Group (2): DEN group: Rats were given DEN at a dose of $(20 \mathrm{mg} / \mathrm{kg}$ b.w/day/12 weeks) orally via gavage (ElShahat, et al., 2012).

2.3.3 Asparagus group: Rats were given Asparagus daily orally by gavage at a dosage of $(200 \mathrm{mg} / \mathrm{kg} \mathrm{b.w} / 18$ weeks $)$ (Agrawal et al., 2008).

2.3.4 Group (4): DEN + Asparagus group (treatment): Rats were given DEN at a dose of $(20 \mathrm{mg} / \mathrm{kg}$ b.w/day $/ 12$ weeks $)$ orally via gavage then Asparagus was given at a dosage of $(200 \mathrm{mg} / \mathrm{kg} \mathrm{b.w} / 6$ weeks) orally via gavage.

2.3.5 Group (5): Asparagus + DEN group (protector): Rats were given Asparagus at a dosage of $(200 \mathrm{mg} / \mathrm{kg}$ b.w $/ 6$ weeks) orally via gavage, then DEN was given at a dose of (20 mg/kg b.w/day/12 weeks) orally via gavage, with Asparagus being consumed continuously.

2.4. Sampling:

Blood and liver tissue samples were collected after overnight fasting of rats from all groups at the experiment end.
2.4.1 Blood samples: A blood samples were collected from retro-orbital plexus of the eyes. After allowing the blood to clot, it was centrifuged for 15 minutes at 3,000 rpm. Sera were aspirated in dry sterile tubes using an automated pipette and kept at $-20{ }^{\circ} \mathrm{C}$ in a deep freezer until biochemical parameters were determined.

2.4.2Tissue sample: The liver was removed easily, washed in ice cold saline, snap-frozen in liquid nitrogen, and deposited at $-80 \mathrm{oC}$. One gram of liver tissue was cut and minced into small parts, homogenized with a glass homogenizer in 9 volumes of ice-cold $0.05 \mathrm{mM}$ potassium phosphate buffer ( $\mathrm{pH} 7.4)$ to make $10 \%$ homogenates, and centrifuged at $4^{\circ} \mathrm{C}$ for 15 minutes at 6000 r.p.m. The antioxidant activity of the supernatant was determined directly.

2.5. Analysis:

\subsubsection{Liver Enzymes:}

Biochemical parameters were estimated to evaluate liver enzymes activity as following: alanine aminotransferase (ALT) according to Fischbach, et al., (1992), aspartate amino transferase (AST) according to Fischbach, et al., (1992) and Alkaline Phosphatase (ALP) according to Klin, (1970) by using Human kits for diagnosis (Germany).

2.5.2 Antioxidant enzymes:

Furthermore, the supernatant of hepatic tissue homogenate $(10 \%)$ was used for estimation of catalase (CAT) activity according to Fossati.et al., (1980) and Superoxide dismutase (SOD) activity according to Nishikimi et al., (1972) by using Biodiagnostic kit (Cairo, Egypt).

2.5.3 IL-6 level:

According to Hirano, the Il-6 level in serum was determined using the Quantikine Elisa kit for rat Il-6 Immunoassay, R\&D Systems, Inc, USA (1998).

2.5.4 Molecular analysis:

In rat liver, real-time quantitative polymerase chain reaction analysis (real-time qPCR) was used to determine the mRNA expression contents of p53. The QIAamp RNA Blood Mini Kit was used to extract total RNA from homogenised liver samples (Qiagen, USA). A NanoDrop 2000 spectrophotometer was used to verify the concentration and purity of the extracted RNA (Thermo Scientific, USA). QuantiTect Reverse Transcription Kit was used to prepare reverse transcripts from the extracted RNA (Qiagen, USA). A QuantiTect SYBR Green PCR kit was used to measure gene expression in real-time (Qiagen, USA). The primer was pre-made and issued by the company (Invitrogen USA). P53's relative quantification was measured using GAPDH as a reference gene. $2 \mu 1$ of primer, $12.5 \mu 1$ of $2 \mathrm{x}$ QuantiTect SYBR Green PCR Master Mix, $8.5 \mu 1$ of RNase-free water, and $2 \mu 1$ of cDNA were used in PCR reactions. Cycling began at $95^{\circ} \mathrm{C}$ for 15 minutes, accompanied by 40 cycles of $94^{\circ} \mathrm{C}$ denaturation for 15 seconds, $55^{\circ} \mathrm{C}$ annealing for 30 seconds, and $72^{\circ} \mathrm{C}$ extension for 30 seconds, all followed by a melt curve.

\begin{tabular}{ll}
\hline Gene & Primer sequence \\
\hline P53 & Forward primer :5'- CGCAAAAGAAGAAGCCACTA-3 \\
& Reverse primer:5'-TCCACTCTGGGCATCCTT-3 \\
GAPDH & Forward primer :5'- TGATTCTACCCACGGCAAGTT-3 \\
& Reverse primer:5'-TGATGGGTTTCCCATTGATGA-3 \\
\hline
\end{tabular}

\subsection{Statistical analysis:}

All of the results were analyzed by SPSS software (version 19). Hypotheses were evaluated by using One-way analysis of variance (ANOVA), preceded by the least significant difference (LSD) test to find discrepancies between group means. Significance minimum degree was set at $\mathrm{P}$-values of 0.05 . 


\section{RESULTS}

\subsection{Liver enzymes:}

The results of this study (fig 1 and 2) revealed that rats administrated DEN significantly increase ALT, AST, and ALP activities when compared with normal control group. Administration of AR to DEN group(treated) resulted in significant decrease in ALT, AST, and ALP activities when compared to the DEN group(non-treated) and when compared to both the DEN group and the $A R$ treated group.

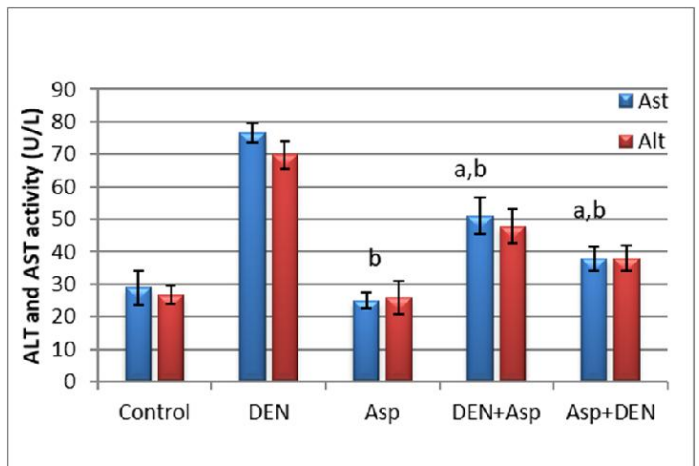

Figure 1 Serum ALT, AST activity (U/L) in control, DEN group and Asparagus racemosus treated groups of male albino rats.

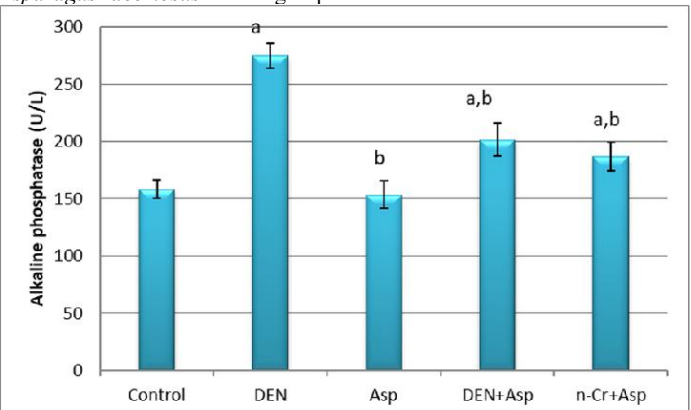

Figure 2 Serum ALP activity (U/L) in control, DEN group and Asparagus racemosus treated groups of male albino rats.

\subsection{Antioxidant enzymes:}

Rats received DEN revealed a significant reduction in SOD and CAT activity compared to the negative group. While DEN-treated with AR group, showed a significant increase in SOD and CAT activity when compared to the DEN group. Data also documented that protection with AR showed a significant increased the activity of SOD and CAT compared with DEN treated group and AR treated group in (fig.3, 4).

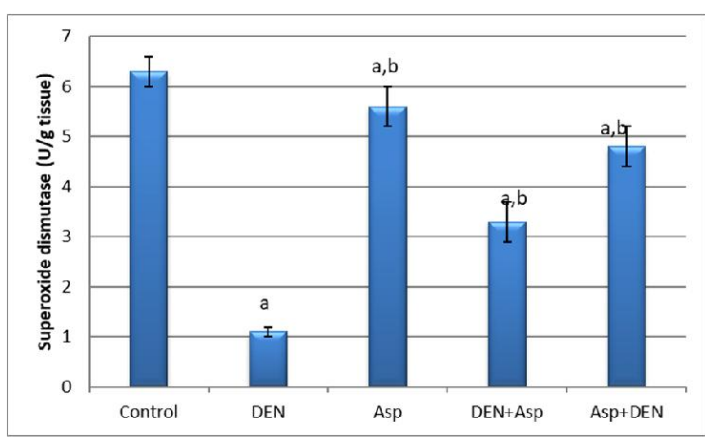

Figure 3 Hepatic SOD activity (U/g) in control, DEN group and Asparagus racemosus treated groups of male albino rats.

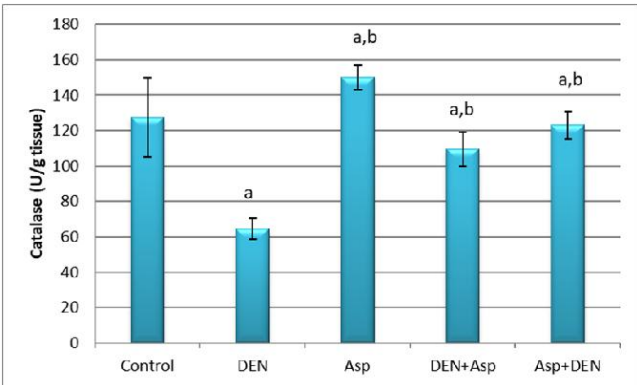

Figure 4 Hepatic CAT activity (U/g) in control, DEN group and Asparagus racemosus treated groups of male albino rats.

\subsection{IL-6 level:}

IL-6, as pro-inflammatory cytokine, was significantly elevated in DEN treated group when compared with negative control rats, this elevation was significantly decreased in rats induced $\mathrm{HCC}$ and treated with AR when compared to DEN treated group. AR protected group showed significant decrease when compared to DEN group fig (5).

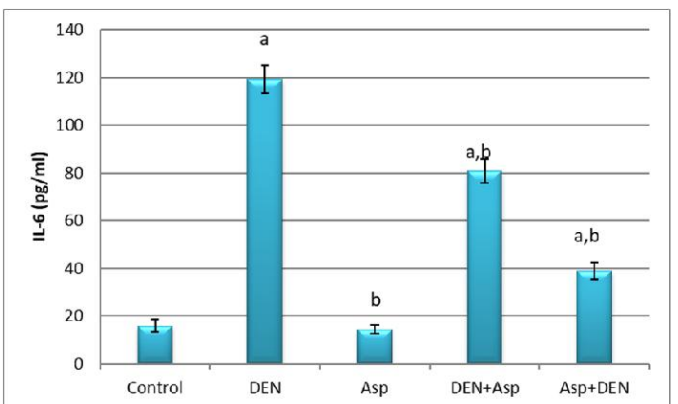

Figure 5 IL-6 activity $(\mathrm{pg} / \mathrm{ml})$ in control, DEN group and Asparagus racemosus treated groups of male albino rats.

3.4. P53 gene expression:

When compared to the negative control group, the tumor suppressor P53 level was significantly upregulated in the DEN treated group. In comparison to the DEN-treated group, rats with $\mathrm{HCC}$ were treated with $\mathrm{AR}$ and the protected group showed a substantial increase in P53 expression (Fig.6).

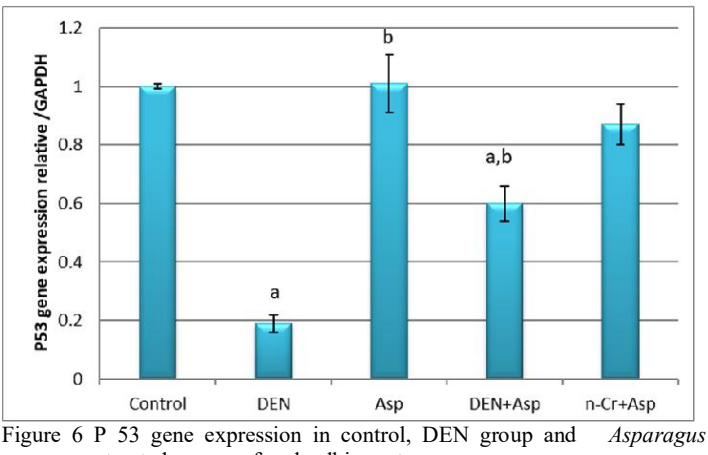
racemosus treated groups of male albino rats.

\section{DISCUSSION}

(HCC) is the most prevalent primary carcinoma in the world (70-90 percent) (Baig et al., 2019). It becomes important to go looking out and develop alternative therapeutic agents. Medicinal plants are the source of various anticancer agents including taxol, vinblastine, vincristine, etoposide, etc. they're simpler and safer and don't have side effects as compared to synthetic drugs (Gullett et al., 2010). 
AR extracts has proved to possess various pharmacological properties and a potent therapeutic agent (Hasan, et al., 2016). The root extract of AR was screened for phytochemical constituents to determine the presence of alkaloids, flavanoids, tannins, phytosterols, glycosides (Selvaraj, et al., 2019). Taken orally was the only and most natural way to deliver the Asparagus racemosus extract. Orally administered chemicals/drugs pass via the intestinal wall and liver before being transferred to the target site through the bloodstream. Since this was a study on preventing hepatocarcinogenesis, the plant extract was given orally (Agrawal et al., 2008). Asparagus racemosus aqueous root extract has been shown to have the ability to serve as an effective formulation for preventing hepatocarcinogenesis (Agrawal et al., 2008). The enzyme leakage and cellular damage have a strong relationship (Sherawat and Sultana, 2006).

The activity of ALT, AST, and ALP were increased in DENtreated albino rats than in the negative control group, according to our findings. In contrast to the DEN-treated rats, Asparagus racemosus administration pre or post DEN treatment reduced the activities of AST, ALT, and ALP enzymes. Generally, liver damage induced by DEN is related to the disruption of liver cell metabolism and membrane instability and subsequently causes distinctive changes in the activities of serum enzyme (Abozaid et al., 2019). This is due to the fact that DEN acts mainly as a liver toxin in rats, mice, rabbits, and dogs, causing extreme liver necrosis. In DEN administrated rats the subsequent injured liver is characterized by completely damaged parenchyma and apparently injured liver cell areas (Barnes and Magee, 1954, Tolba et al., 2015). The most sensitive markers used in the diagnosis of hepatic injury are ALT, AST, and ALP (Sallie et al., 1991). The increase in serum activity and subsequent decrease in tissue activity may be due to cytosolic enzyme leakage into the circulatory system as a result of hepatocellular damage during ethanol and DEN administration. This indicates the onset of hepatocellular damage as a result of liver dysfunction and disruption of the biosynthesis of the enzymes listed, as well as a change in the permeability of the liver membrane. Treatment with Asparagus racemosus substantially reduced the elevation of these markers to normal levels, possibly by preserving the hepatocellular membrane integrity. This is a sign that Asparagus racemosus has hepatoprotective properties. In contrast to the negative control group, DEN treated albino rats showed decrease in CAT and SOD activity. In DENtreated rats, pre- and post-administration of an aqueous extract of Asparagus racemosus reversed the DEN-induced decline in enzyme activity. The combination of DEN and Asparagus racemosus aqueous root extract resulted in a significant increase in CAT activity. Following treatment with DEN, there was a significant increase in antioxidant and SOD activity after treatment with aqueous extract. The biochemical findings also show that pretreatment of albino rats with an aqueous extract of Asparagus racemosus decreases the oxidative stress and hepatotoxicity caused by DEN administration. (Aggrawel et al., 2008). Following DEN administration, there was a significant increase in lipid peroxidation (LPO) and a significant decrease in SOD and CAT levels, suggesting oxidative stress induced by the reactive metabolites of DEN. Furthermore, the observed reductions in enzymatic antioxidants (SOD and CAT) during DEN administration suggest that the liver's antioxidant defense mechanism has been completely disrupted. The decrease in these enzyme activities may be due to a reduction in biosynthesis or an overuse of these enzymes in trapping the free radicals generated. Asparagus racemosus administration resulted in a substantial reduction in LPO as well as an improvement in the status of enzymatic antioxidants in the liver tissue. Since there are no endogenous cellular antioxidants, the phytochemicals in Asparagus racemosus function as exogenous antioxidants by quenching ROS and preventing further hepatocyte peroxidation. This is due to the recovery of LPO levels as well as the status of enzymic and non-enzymic antioxidants after administration of Asparagus racemosus. Several studies have shown that Asparagus racemosus has antioxidant properties that protect the liver from damage caused by electromagnetic radiation. Against lipid peroxidation, the antioxidant potential was well described (Gautam et al., 2004, Selvaraj et al., 2019)

Hepatocarcinogenesis mechanism that induced by DEN may be the product of cytochrome P-450 isozymeshydroxylating DEN to make it bioactive, which then interacts with DNA to cause bases ethylation. Base pairing can be disrupted by ethyl DNA adducts, resulting in mutations and the activation of proto-oncogenes and the inhibition of tumor suppressor genes such as p53, both of which can contribute to hepatocarcinogenesis. Although recent research has shown that continuous intrahepatic necro-inflammatory changes occur during the DEN-induced carcinogenesis process, the inflammatory response pathogenic significance is unknown (Matsuda et al., 2005).

The p53 gene serves as a genome guardian and is one of the most important regulators of cell proliferation, growth suppression, and transformation. Inactivation of the p53 tumor suppressor gene can be a common occurrence during tumorigenesis. Interestingly, mutations in the p53 gene have been shown to occur at various stages of malignant transformation, leading to tumor initiation, promotion, aggressiveness, and metastasis in different ways (Van et al., 1997). Furthermore, Levine et al. (1991) reported that changes in the p53 gene appeared to be essential for hepatocarcinogenesis. DEN decreased p53 levels in the rat liver, according to our findings. DNA-strand breaks, which were caused directly by this genotoxic agent, are thought to be the specific signals for $\mathrm{p} 53$ expression. This could explain the induction of $\mathrm{p} 53$ by DEN, which is clastogenic inside the rat liver due to the formation of various DNA-adducts with varying effects on DNA-helix distortion, DNA-replication, and gene mutation induction. On the other hand, our findings showed that there were few mutations in the 553 gene in rats supplemented with Asparagus racemosus pre or post DEN treatment, particularly when taken at the same time. In comparison to the controls, pre and post treatment with Asparagus racemosus aqueous root extract results in substantial inhibition of hepatotoxicity, as well as DEN triggered malignancy. These results agree with Mishra and Verma, (2017) who documented that Aqueous extract of the roots of Asparagus racemosus has the potential to act as an effective formulation to prevent hepatocarcinogenesis induced by treatment with DEN Immunohistochemical staining of the hepatic tissues of rats treated with DEN showed the presence of clusters of cells expressing the mutated p53 protein, whereas an absence of mutated p53 foci was observed in Wistar rats pretreated with the aqueous extract of the roots of Asparagus racemosus. So, Wistar rats which were pretreated with the aqueous extract of the roots of Asparagus racemosus prevented the incidence of hepatocarcinogenesis.

There was an elevation in IL-6 observed in cirrhosis and hepatocarcinogenesis (Xiang et al., 2018). Though resident immune cells secrete the majority of IL 6 , hepatocytes contribute to the total expression of IL 6 in the liver microenvironment. (Park et al., 2010) As a result, IL 6 
accelerates compensatory hepatocyte proliferation, primarily as a result of tumor progression. (Gosain et al., 2019). Within the present study, hepatic pro-inflammatory biomarker, IL- 6, was significantly increased at DEN group due to the inflammation induced within the hepatic tissue because of DEN inflammatory known effect.

\section{CONCLUSION}

Based on these findings, we may conclude that Asparagus racemosus aqueous root extract is a beneficial food constituent that may help in amelioration liver status inhepatocarcinogenes cases and it has good antioxidant and anti-inflammatory properties that help in improve body cells conditions.

\section{REFERENCES}

1. Abouzaid, O.A.R., Elsonbaty, S.M., Moawad, F.S. and Abdelghaffar, M.M.2019.The ameliorative effects of Spirulinaplatensis against Diethylnitrosamine induced hepatotoxicity in rats. BVMJ, 36 (1):262-271.

2. Agrawal, A., Sharma, M., Rai, S.K., Singh, B., Tiwari, M., and Chandra, R. 2008. The Effect of the Aqueous Extract of the Roots of Asparagus racemosus on Hepatocarcinogenesis initiated by Diethylnitrosamine. Phytotherapy Research, 22(9):1175-1182.

3. Aly, S.M., Fetaih, H.A., Hassanin, A.A.I., Abomughaid, M.M., and Ismail, A.A. 2019.Protective Effects of Garlic and Cinnamon Oils on Hepatocellular Carcinoma in Albino Rats. Analytical Cellular Pathology, Article ID 9895485, 15 pages.

4. Baig, B., Halim, S., Farrukh, A., Greish, Y. and Amin, A. 2019.Current status of nanomaterial-based treatment for hepatocellular carcinoma. Biomedicine \& Pharmacotherapy 116,1:12.

5. Barnes, J.M. and Magee, P.N.1954. Some toxic properties of dimethylnitrosamine. $\mathrm{Br} \mathrm{J}$ Ind Med; 11: 167-174.

6. Bhutani, K.K., Paul, A.T., Fayad, W. and Linder, S. 2010. Apoptosis inducing the activity of steroidal constituents from Solanumxanthocarpum and Asparagus racemosus. Phytomedicine, 17(10):789793.

7. El-Shahat, M., El-Abd S., Alkafafy, M. and El-Khatib, G. 2012. Potential chemoprevention of diethylnitrosamine-induced hepatocarcinogenesis in rats: myrrh (Commiphoramolmol) vs. turmeric (Curcuma longa). Acta Histochem.114(5):421-8.

8. Estes, C., Razavi, H., Loomba, R., Younossi, Z. and Sanyal, A. J. 2018.Modeling the epidemic of nonalcoholic fatty liver disease demonstrates an exponential increase in burden of disease. Hepatology 67, 123-133.

9. Fischbach, F. and Zawata, B. 1992. Klin. Lab. 38, 555561.

10. Fossati, P., et.al .1980 Clin. Chem. 26, $227-231$.

11. Gautam, M., Diwanay, S., Gairola, S., Shinde, Y., Patki, P. and Patwardhan, B.2004.Immunoadjuvant potential of Asparagus racemosusaqueous extract in experimental system. J Ethnopharmacol.;91(2-3):251255.

12. Gomase, V.S. and Sherkhane, A.S. 2010. Isolation, structure elucidation and biotransformation studies on secondary metabolites from Asparagus racemosus. International Journal of Microbiology Research, 2(1):7-9.

13. Gosain, R., Anwar, S., Miller, A., Iyer, R. and Mukherjee, S.2019. Interleukin-6 as a biomarker in patients with hepatobiliary cancers. J Gastrointest Oncol 10: 537-545.

14. Gullett, N.P., Ruhul, Amin, A.R.M., Bayraktar, S., Pezzuto, J.M., S., Khuri, F.R., Aggarwal, B.B., Surh, Y. and Kucuk, O. 2010. Cancer prevention with natural compounds. Seminars in Oncology, 37(3):258-281.

15. Hann, H.W., Wan,S., Myers R.E., Hann,R.S., Xing,J., Chen, B., and Yang, H.2012. Comprehensive Analysis of Common Serum Liver Enzymes as Prospective Predictors of Hepatocellular Carcinoma in HBV Patients.PLoSOnev.7(10); 1-10.

16. Hassan, H.A., El-Gharib, N.E. and Azhari, A.F.2016. Role of natural antioxidants in the therapeutic management of hepatocellular carcinoma. Hepatoma Res; 2:216-23.

17. Hasan, N., Ahmad, N., Zohrameena,S., Khalid, M. and Juber Akhtar. 2016. Asparagus racemosus: for medicinal uses \& pharmacological actions. International Journal of Advanced Research.4(3):259267.

18. Hassan, S.K., Mousa, A.M., Eshak, M.G., Farrag, A.H., Badawi, A.M.2014. Therapeutic and chemopreventive effects of nanocurcumin against diethylnitrosamine induced hepatocellular carcinoma in rats. Int J Pharm Sci.; 6:54-62.

19. Hirano, T. 1998. Interleukin 6 in The Cytokine Handbook, 3rd. ed. Academic Press,New York, p. 197.

20. International Agency for Research on Cancer. GLOBOCAN 2018

21. Kongkaneramit, L., Witoonsaridsilp, W., Peungvicha, P., Ingkaninan, K., Waranuch, N. and Saisuta, N. 2011. Antioxidant activity and antiapoptotic effect of Asparagus racemosus root extracts in human lung epithelial H460 cells. Experimental and Therapeutic Medicine, 2(1):143-148.

22. Levine, A.j., Momand, J. and Finley C. 1999.The p53 tumor suppressor gene. Nature; 351:453-456.

23. Liovet, J.M., Kelley, R.K., Villanueva, A., Singal, A.G., Pikarsky, E., Roayaie S., Lencionh, R., Koike, K., Zucman- Rossi, J. and Richard, S. Finn, R.S. 2021. Hepatocellular Carcinoma.NatureReveiwes| Disease Primers 7:6.

24. Mandal, A.K., Das, S., Mitra, M., Chakrabarti, R.N., Chatterjee, M. and Das, N.J. 2008. Vesicular flavonoid in combating diethylnitrosamine induced hepatocarcinoma in rat model. ExpTherOncol.; 7(2):123-33.

25. Matsuda, M., Nakamoto, Y., Suzuki, S., Kurata, T.and Kaneko, S. 2005. Interferon- $\gamma$-mediated hepatocarcinogenesis in mice treated with diethylnitrosamine. Lab Invest 85: 655-663.

26. Mitra, S.K., Prakash, N.S. and Sundaram, R. 2012. Shatavarins (containing ShatavarinIV) with anticancer activity from the roots of Indian Journal of Asparagus racemosus Pharmacology, 44(6):732-736.

27. Mishra, J.N. and Verma, N.K. 2017. Asparagus racemosus: chemical constituents and pharmacological activities- a review. Ejbps,Volume 4, Issue 6, 207-213.

28. Nishikimi, M., Roa, N.A., and Yogi, K. 1972. Biochem. Bioph. Res. Common., 46, 849 - 854.

29. Park, E.J., Lee, J.H., Yu, G.Y., He, G., Ali, S.R., Holzer, R.G., Osterreicher, C.H., Takahashi, H. and Karin, M. 2010. Dietary and genetic obesity promote liver inflammation and tumorigenesis by enhancing IL-6 and TNF expression. Cell 140: 197-208.

30. Rajeshwar, Y., Sreekanth, T., Shyamsunder, B. and Tejaswi, D. B. 2014. Investigation of Phytoconstituents, TLC Profile and Antimicrobial Activity of Methanol Extract of Asparagus 
racemosuswilld.Roots. International Journal of Pharmacognosy and Phytochemical Research, 6(1):128-132.

31. Rebel, H., Mosnier, L.O. and Berg, R.J. 2001. p53 Positive foci as indicators of tumor risk in ultravioletexposed hairless mice: kinetics of induction, effects of DNA repair deficiency, and p53 heterozygosity. Cancer Res 61: 977-983.

32. Rotter, V., Foord, O. and Navot, N. 1993. In search of the functions of normal p53 protein. Trends Cell Biol 3: $46-49$.

33. Roy, S. R. and Gadad, P.C. 2016. Effect of $\beta$-asarone on diethylnitrosamine-induced hepatocellular carcinoma in rats. Indian Journal of Health Sciences and Biomedical Research (KLEU), vol. 9, no. 1, p. 82.

34. Sallie, R., Tredger, J.M. and Willam, R. 199. Drugs and the Liver. Biopharm Drug Dispos 12: 251-259.

35. Schulze, K., Imbeaud, S., Letouzé,E., Alexandrov, L.B, Calderaro, J., Rebouissou,S.,Couchy,G., Meiller,C., Shinde,J., Soysouvanh,F., Calatayud,A.L., Pinyol, R., Pelletier, L., BalabaudL, Laurent, A., Blanc,J.F. 2015. Exome sequencing of hepatocellular carcinomas identifies new mutational signatures and potential therapeutic targets. Nat. Genet. 47, 505-511.

36. Sehrawat, A. and Sultana, S. 2006. Evaluation of possible mechanisms of protective role of Tamarixgallica against DEN initiated and 2-AAF promoted hepatocarcinogenesis in male Wistar rats. Life Science 79: 1456-1465.

37. Selvaraj, K., Sivakumar, G., Veeraraghavan, V.P., Dandannavar, V.S., Veeraraghavan, G.R. and
Rengasamy, G. 2019. Asparagus racemosus - A Review. Sys Rev Pharm.;10(1):87-89.

38. Sharma, S., Ramji, S., Kumari, S. and Bapna, J.S. 1996. Randomized Controlled Trial of Asparagus racemosus (Shatavari) as a Lactogogue in Lactational Inadequacy. Indian Pediatrics, 33(8):675-677.

39. Sluss, H.K. and Jones, S.N. 2003. Analysing p53 tumour suppressor functions in mice. Expert OpinTher Targets 7: 89-99.

40. Tolba R, Kraus T, Liedtke C, Schwarz M and Weiskirchen R. 2015. Diethylnitrosamine (DEN)induced carcinogenic liver injury in mice. Laboratory Animals, Vol. 49(S1) 59-69.

41. Uma, B., Prabhakar, K. and Rajendran, S. 2009. Anticandidal Activity of. Indian Journal of Asparagus racemosus Pharmaceutical Sciences, 71(3):342-343.

42. Van Gijssel, H.E., Maassen, C.B., Mulder, G.J. and Meerman, J.H. 1997. p53 protein expression by hepatocarcinogens in the rat liver and its potential role in mitoinhibition of normal hepatocytes as a mechanism of hepatic tumour promotion. Carcinogenesis; 18 Suppl 5:1027-1033.

43. Villanueva, A. 2019. Hepatocellular carcinoma. N. Engl.J. Med. 380, 1450-1462.

44. Xiang, D.M., Sun, W., Ning, B.F., Zhou, T.F., Li, X.F., Zhong, W., Cheng, Z., Xia, M.Y., Wang, X. and Deng, X. 2018. The HLF/IL- 6/STAT3 feedforward circuit drives hepatic stellate cell activation to promote liver fibrosis. Gut 67: 1704-1715. 